\title{
ORGANIZATIONAL AND PERSONALITY EFFECTS ON MANAGERS' JOB STRESS: Is It Different for Malaysian Men and Women?
}

\author{
AizzatMohd. Nasurdin \\ T. Ramayah \\ S.Kumaresan
}

\begin{abstract}
The purpose of this paper is to determine the influence of organizational variables (conflict, blocked career, alienation, work overload, and unfavorable work environment) and personality variables (neuroticism, extraversion, openness, agreeableness, and conscientiousness) on job stress among managers working in the electronics sector in 4Malaysia and whether this relationship varies according to their gender. Analyses of 285 responses using hierarchical regression revealed that four of five organizational variables (blocked career, alienation, work overload, and conflict) had significant positive effects on job stress. In terms of the personality traits, neuroticism and conscientiousness were found to be significantly and positively related to stress. Extraversion and agreeableness, on the other hand, had significant negative effects on job stress. Gender was found to moderate the effects of all the independent variables on job stress at the 0.01 level. Implications for managerial practice and future research are discussed.
\end{abstract}

Keywords: gender; job stress; Malaysia; managers; moderating effects; organizational factors; personality traits 


\section{Introduction}

Job stress has long been an important concept in the organizational study of the responses employees have to their surroundings. The many challenges in the work environments, characterized by heightened competition, lack of time, more uncontrollable factors, lack of space, continuous technological development, conflicting demands from organizational stakeholders (Hall and Savery 1986), increased use of participatory management and computerization (Murray and Forbes 1986), greater uncertainty, and others have resulted in higher job stress. In the pursuit for organizational excellence, managers need to work under highly stressful circumstances.

Managers in the manufacturing sector have been found to be experiencing high stress (Jestin and Gampel 2002). The weakening of the global economy during the past few years has resulted in substantial downsizing and retrenchments. Such events among employees in local and foreign firms are inevitable given Malaysia's reliance on the industrial sectors particularly electronics, which account for 60 percent of its total exports (Bank Negara Malaysia 2001). Although there have been several studies on job stress within the Malaysian context (for instance, Kuan 1994; Bat 1995; Aun 1998; Yahya 1998), these studies have been somewhat fragmented. Specifically, the objectives of this study are: (1) to gauge the extent to which organizational variables (conflict, blocked career, alienation, work overload, and unfavorable work environment) and individuals' personality traits (neuroticism, extraversion, agreeableness, openness, and conscientiousness) affect job stress and, (2) to examine whether gender moderates the relationship between the predictor variables and job stress.

\section{Review of Literature}

\section{Organizational Sources of Stress}

Job stress has been defined as the nonspecific response of the body to any demands made upon it (Selye 1976). It is considered to be an internal state or reaction to anything a person consciously or unconsciously perceive as a threat, either real or imagined(Clarke and Watson 1991). Robbins (2001) defines stress as a dynamic condition in which the individual is confronted with an opportunity, constraint, or demand related to what he or she desires and for which the outcome is perceived to be both uncertain and important. Stress can be caused by environmental, organizational, and individual variables (Matteson and Ivancevich 1999; Cook and Hunsaker 2001). Organizational variables have been known to create stress for employees at the workplace (Greenhaus and Beutell 1985). Among the numerous organizational sources of stress, only five variables were investigated in this studynamely conflict, blocked career, alienation, work overload, and unfavourable work environment.

Role conflict has been found to have a positive relationship with job stress (Roberts et al. 1997). When individuals are required to play two or more roles that work against each other, they are likely to experience job stress. This is because role conflicts create expectations that may be hard to reconcile. Previous scholars (for instance, Foot and Venne 1990; Rahim 1996) discovered a positive relationship between barriers to career advancement and job stress. When employees perceived a lack of career opportunities, they are likely to feel uncertain about their future in the organization, which in turn, are likely to induce stress. Working alone on one's 
job without social support from one's peers and supervisors would lead to job stress (Mirovisky and Ross 1986; Thoits 1995; Eugene 1999). According to Kanungo (1981), when workers believe there is a separation between their own job and other work related context, a sense of frustration that finally manifested in a behavioral state of apathy is likely to occur. This is particularly intense for employees with high social needs. Work overload both quantitatively and qualitatively has been empirically linked to a variety of physiological, psychological, and behavioral strain symptoms (Beehr and Newman 1978; Miller and Ellis 1990; Roberts et al. 1997). According to Greenhaus et al. (1987), heavy workload lowers one's psychological well-being resulting in job stress. Additionally, a work environment associated with unpleasant organizational climate, lack of privacy, a lot of hassle in conducting work, and physical distractions can result in higher stress (Miller and Ellis 1990; Eugene 1999).

\section{Personality Traits as Sources of Stress}

Past studies have indicated the potential impact of personality traits on job stress (Goldberg 1993; Deary and Blenkin 1996). Over the years, five personality dimensions that have been identified as being able to explain a majority of the variance in behavioral outcomes are neuroticism, extraversion, openness, agreeableness, and conscientiousness (John and Srivastava 1999). Neuroticism involves a sense of emotional instability and negative affect (Costa and McCrae 1985; John and Srivastava 1999). People with neuroticism traits are those who experience more negative emotions, which would be reflected in poor job attitudes, and high levels of job stress. According to Tellegen (1985), neuroticism functions as a warning system, activated by perceptions of environmental uncertainty, and tends to interfere with one's ability to adapt. Thus, individuals with elevated levels of neuroticism would be expected to be associated with higher stress since they are more likely to view stimuli as a threat to them. Prior studies have provided empirical evidence on the positive relationship between neuroticism and job stress (Tellegen 1985; Deary and Blenkin 1996; Birch and Kamali 2001).

Extraversion relates to social facility, ambition, energy, enthusiasm, dominance, and positive affectivity (Watson and Clark 1997). Individuals who are high in extraversion exert more leadership, being more physically and verbally active, and to be more friendly and outgoing around others than most people tend to be (Costa and McCrae 1992). According to Moberg (2001), extraversion taps the individual's predispositions to view his/her actions as positive, emotionally satisfying, and effectual. Such information seems to suggest that individuals who are high on extraversion are more likely to experience lower stress since they are more likely to perceive stimuli in a positive and favorable manner. Birch and Kamali (2001) discovered that extraversion had a negative relationship with job stress.

Openness involves intellectual activity, cultural sophistication, thoughtfulness, originality, imagination, need for variety, and preference for cognitive complexity (McCrae 1996). According to Costa and McCrae (1992), the openness factor include behaviors that convey a willingness to entertain and experience novelty, whether in interests, people, situations, values, or ideas, and a sense of divergent and creative thinking. According to Moberg (2001), individuals who havehigh openness are less likely to emphasize rules, 
order, and conformity, more flexible, and find it is easier to understand others' point of views. Hence, one would expect individuals with elevated levels of openness to be associated with lower stress since they are able to adapt to the different environmental stimuli.

Agreeableness reflects the ability to be kind, considerate, likeable, cooperative, and helpful (Graziano and Eisenberg 1997). People who are high in agreeableness are sympathetic, helpful, and cooperative, whilst those who are low in agreeableness are antagonistic, skeptical, and competitive (Costa and McCrae 1992). According to Moberg (2001), individuals who have high agreeableness are more likely to emphasize cooperation and consideration for others. Since highly agreeable individuals tend to be friendly to other people, they are more likely to experiencelower stress. Finally, conscientiousness, has been defined as social conformity and impulse control, cautiousness, orderliness, persistence, dependability, responsibility, carefulness, and preference for predictability (Hogan and Ones 1997). Those who are high in conscientiousness are thought to exhibit high levels of perseverance, low impulsiveness, a strong disposition toward achievement, and a responsible orientation toward work (Moberg 2001). Costa and McCrae (1992) viewed conscientiousness as a group-based responsibility relating to activities of planning, organizing, and task completion. Deary and Blenkin (1996) found that conscientiousness contributed to positive feelings of personal achievement since highly conscientious individuals have a greater inclination to apply themselves to solving the practical aspects of a stressor. Moberg (2001) added that individuals with high conscientiousness are able to address conflict situations promptly and resolve dis- putes in an organized fashion that benefits the group. Such information seems to suggest that conscientiousness would be negatively related to job stress.

The Moderating Role of Gender on The Relationship Between Stressors (Organizational and Personality) and Job Stress

It is widely believed that women as a group are more stressed and experience different kind of jobstress than men (Miller and Ellis 1990). According to Jick and Mitz (1985), women experience psychological distress namely, depression, emotional discomfort more frequently than men. This inclination to experience higher stress among women may be associated with the multiple role and conflicting demands imposed by the domestic and employment duties. According to Terborg (1977), working women particularly those in managerial positions frequently experience role overload and conflicts resulting in higher stress because they have to undertake their job responsibilities and at the same time maintain their domestic role as wife and mother. Haw (1982) further added that for many women, family demands and obligations had to take precedence over work. Therefore, given their heavy workload, working women rather than men aremore likely to experiencehigher stress. Additionally, women of the East are more likely to experience higher stress compared to their counterparts from Western countries. One plausible explanation for greater stress among Eastern women may be due to the fact that women tend to be victims of various forms of discrimination (Northcraft and Gutek 1993), and sex-role stereotyping (Ngo and Tsang 1998). For instance, in Taiwan, men are accorded a wider range of opportunities and authority 
Mohd. Nasurdin et al.-Organizational and Personality Effects on Managers' Job Stress

over women (Farh et al. 1997). Similarly, in Malaysia, when resources are limited, families give sons priorityand preferences in gaining an education (Mansor 1994). Within such a context, women's involvement in organizational activities may be somewhat restricted, thereby, resulting in higher stress.

\section{Theoretical Framework and Hypotheses}

\section{Conceptualization of Variables}

Based on the discussion made in the review of literature subsection, the criterion variable for this study is job stress. The predictor variables consisted of organizational factors and personality traits of the individuals. The relationships between the variables are depicted in Figure 1.

Figure 1. Conceptual Framework of the Study

\section{Hypotheses}

From the model depicted in Figure 1, the three major hypotheses are as follows:

$H_{1}$ : Organizational variables (conflict, blocked career, alienation, work overload, and unfavorable work environment) will be positively related tojob stress.

$H_{2}$ : Personality traits (extraversion, agreeableness, openness, conscientiousness except neuroticism) will be negatively related to job stress.

$H_{3}$ : The effects of organizational variables (conflict, blocked career, alienation, work overload, and unfavorable work environment) and personality traits (extraversion, agreeableness, openness, conscientiousness except neuroticism) on job stress will be stronger for women than men.

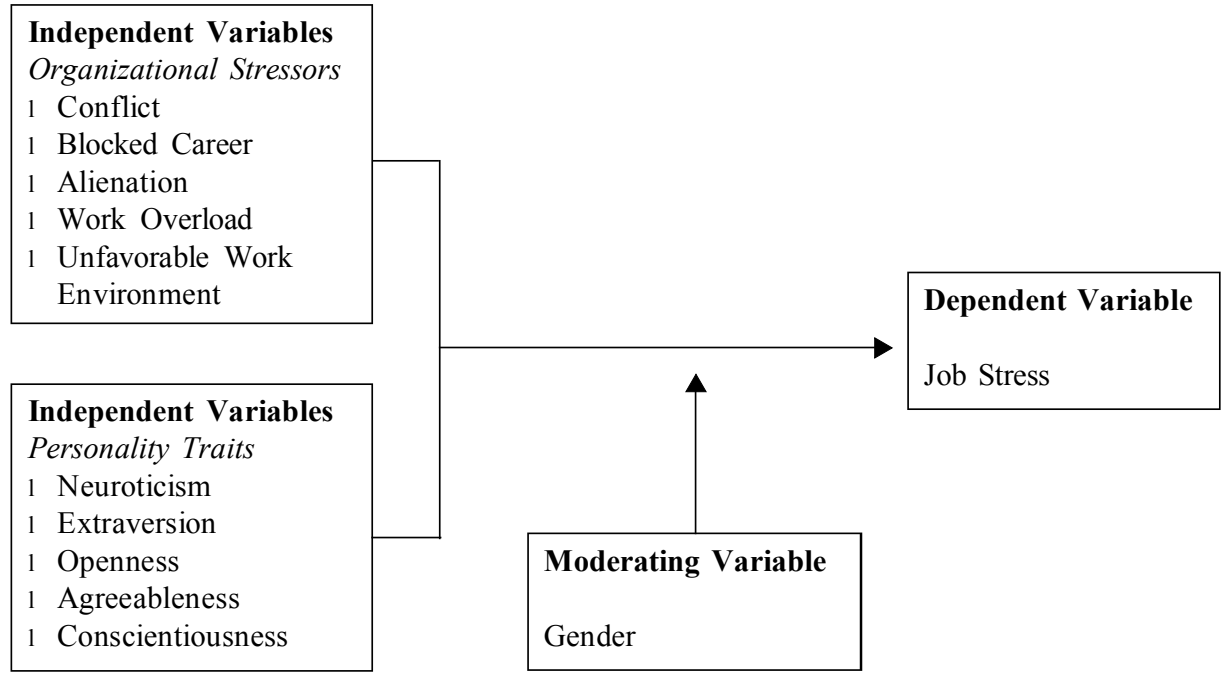




\section{Methodology}

\section{Subjects}

Participants in the study consisted of managers attached to twenty randomly selected electronic firms (both local and foreign) located on the island of Penang, Malaysia. A total of 400 questionnaires were distributed via the help of company officials in proportion to the population of managers in these firms. Respondents were given three weeks to answer the questionnaires.

\section{Measurements}

The predictor variables in this study consisted of organizational and personality variables. Organizational variables include conflict, blocked career, alienation, work overload, and unfavorable work environment. Organizational variables were measured using a 25 -item questionnaire (Davis et al. 2000). Each organizational stressor was measured using 5 -items based on a 5-point Likert response format ranging from (1) "Strongly Disagree" to (5) "Strongly Agree." The mean scores were computed by averaging the scores for all the items associated with a particular stressor. Another set of independent variable relates to personality. Personality variables include extraversion, neuroticism, agreeableness, openness, and conscientiousness. These five dimensions of personality were gauged using 60 -items derived from the NEO Five Factor Inventory (Costa and McCrae 1992). Each personality trait was assessed using 12-items. A 5point scale ranging from (1) "Strongly Disagree" to (5) "Strongly Agree" was utilized. The mean score for each personality trait was obtained by averaging the scores for each of the 12 items. On the other hand, the criterion variable in this study is job stress. Job stress was measured using a 20 -item screening inventory (Goldberg and Hillier 1978) based on a 5point scaleranging from (0) "Never" to (4) "Almost Always." The job stress level for each respondent was computed by summing the total score for all the 20 items. Subsequently, the total scores obtained were averaged in order to gauge the overall job stress level for the sample in accordance to Davis et al.'s (2000) suggestion as follows: 0-25 (coping adequately with job stress), 26-40 (suffering from job stress), 41-55 (suffering from high job stress), 56-80 (experiencing very high job stress or burnout).

Since the instruments were adopted from published studies undertaken by Western scholars, a pilot study was initially conducted. Questionnaires were given to 10 managers from both genders from the targeted pool of respondents. They were asked to answer the questionnaires and interviews were subsequently carried out to check whether the respondents could understand all the questions. Comments given were gathered and some items considered vague by these respondents were later reworded before the final data collection.

\section{Method of Analyses}

Job stress can be influenced by personal factors (Matteson and Ivancevich 1999). Six personal variables (age, marital status, number of children, working experience, and job tenure) were controlled in the statistical analysis following previous researchers (Cooper et al. 1994; Roberts et al. 1997; Smith et al. 1998). The first and second hypotheses were tested using a four-step hierarchical regression (Cohen and Cohen 1975) where the control variables were entered in the first step, followed by the main effects of the five 
Mohd. Nasurdin et al.-Organizational and Personality Effects on Managers' Job Stress

organizational variables (conflict, blocked career, alienation, work overload, and unfavorable work environment) plus the five personality variables (neuroticism, extraversion, agreeableness, openness, and conscientiousness) in the second step. Gender was added into the equation in the third step. In the fourth and final step, the ten interaction terms were entered into the regression equation. The change in the $\mathrm{F}$ value and the significance of the individual parameter was observed. If the interaction term is found to be significant, gender is said to moderate the relationship between the relevant predictor variable and job stress.

\section{Results}

\section{Response and Profile of Respondents}

At the end of the stated period, of the 400 questionnaires sent out, 285 useable responses were obtained representing a response rate of 71.25 percent.

In terms of gender, more than half $(56.8 \%)$ of the sample consisted of males with the remaining 43.2 percent being females. As for age, almost all the respondents $(96.5 \%)$ were 40 years old and below. Regarding marital status, a majority $(52.3 \%)$ of respondents were married with the remaining 47.7 percent being singles. In terms of the number of children, a majority $(50.5 \%)$ of the sample had no children. As for working experience, 54 percent of the sample had been working for more than 6 years. Finally, regarding job tenure, 67.7 percent of the respondents had been in their current job for 5 years or less. Table 1 depicts the reliabilities of the survey instruments. As seen from Table 1, the instruments used in this study were reliable, with coefficients ranging from .80 to .96 , which exceeded the minimum acceptance level of 7 (Nunnally 1978).

The mean scores and standard deviations for each study variable can be seen from Table 2. From Table 2, it can be seen that the mean value for each of the organizational variables ranges from 2.51 to 3.15, with a standard deviation of.63 to.91. The mean score for job stress was 45.38 with a standard deviation score of 10.72. Based on Davis et al.'s (2000) interpretation, this score indicates that respondents in this

Table 1. Reliability Coefficients of the Instruments

\begin{tabular}{lc}
\hline \multicolumn{1}{c}{ Variable } & Cronbach's Alpha Value \\
\cline { 1 - 1 } Conflict & .8747 \\
Blocked Career & .8631 \\
Alienation & .8875 \\
Work Overload & .8518 \\
Unfavorable Work Environment & .8026 \\
Neuroticism & .9580 \\
Extraversion & .9505 \\
Agreeableness & .9104 \\
Openness & .9483 \\
Conscientiousness & .9421 \\
Job Stress & .9182 \\
\hline
\end{tabular}


Gadjah Mada International Journal of Business, May 2004, Vol. 6, No. 2

Table 2. Mean Scores and Standard Deviations of the Variables

\begin{tabular}{|c|c|c|}
\hline Variable & Mean & Std. Deviation \\
\hline Conflict & 2.667 & .716 \\
\hline Blocked Career & 2.806 & .647 \\
\hline Alienation & 2.652 & .839 \\
\hline Work Overload & 3.011 & .736 \\
\hline Unfavorable Work Environment & 2.506 & .663 \\
\hline Neuroticism & 3.146 & .910 \\
\hline Extraversion & 2.989 & .720 \\
\hline Agreeableness & 2.782 & .631 \\
\hline Openness & 2.860 & .704 \\
\hline Conscientiousness & 2.973 & .735 \\
\hline Job Stress & 45.382 & 10.721 \\
\hline
\end{tabular}

study, on the average, experience high job stress.

The correlations among the variables in this investigation can be observed from Table 3. As seen from Table 3, the Pearson's correlation coefficients were wide-ranging (-.010 to .831$)$ across all variables for the sample. Specifically, significant positive relationships exist between the organizational variables and job stress. On the other hand, personality variables except for neuroticism were significantly and negatively correlated with job stress.

The results of the four-step hierarchical regression undertaken to test the first, second, and third hypotheses of this study is depicted in Table 4. As shown in Table 4 , when the five personal variables were entered into the regression equation in the first step, the coefficient of determination $\left(\mathrm{R}^{2}\right)$ was found to be .37 indicating that 37 percent of the variance in job stress is explained by the demographic variables. Specifically, age and number of children had significant positive relationships with job stress whereas job tenure had a significant negative relationship with job stress. In step 2 , by adding the ten independent variables, $R^{2}$ increased to 89.1 percent. This $R^{2}$ change (.521) is significant. This implies that the additional 52.1 percent of variance in job stress is explained by the organizational variables (conflict, blocked career, alienation, work overload, and unfavorable work environment) and personality variables (neuroticism, extraversion, openness, agreeableness, and conscientiousness). As for the independent variables, eight out of the ten organizational and personality variables were found to have an impact on job stress. Of the organizational variables, blocked career $(\beta=$ $.395)$, alienation $(\beta=.298)$, conflict $(\beta=$ $.126)$, and work overload $(\beta=.118)$ were found to have significant and positive relationships with job stress. Unfavorable work environment, however, had no effect on stress. These results provide partial support for the firsthypothesis of the study.

As for the personality variables, four of five dimensions had significant relationships with job stress. Specifically, neuroticism $(\beta=.579)$, and conscientiousness $(\beta=.133)$ were found to have significant and positive relationships with job stress. In contrast, extraversion $(\beta=-.131)$, and agreeableness $(\beta=-.131)$ had significant 
Mohd. Nasurdin etal.-Organizational and Personality Effects on Managers' Job Stress

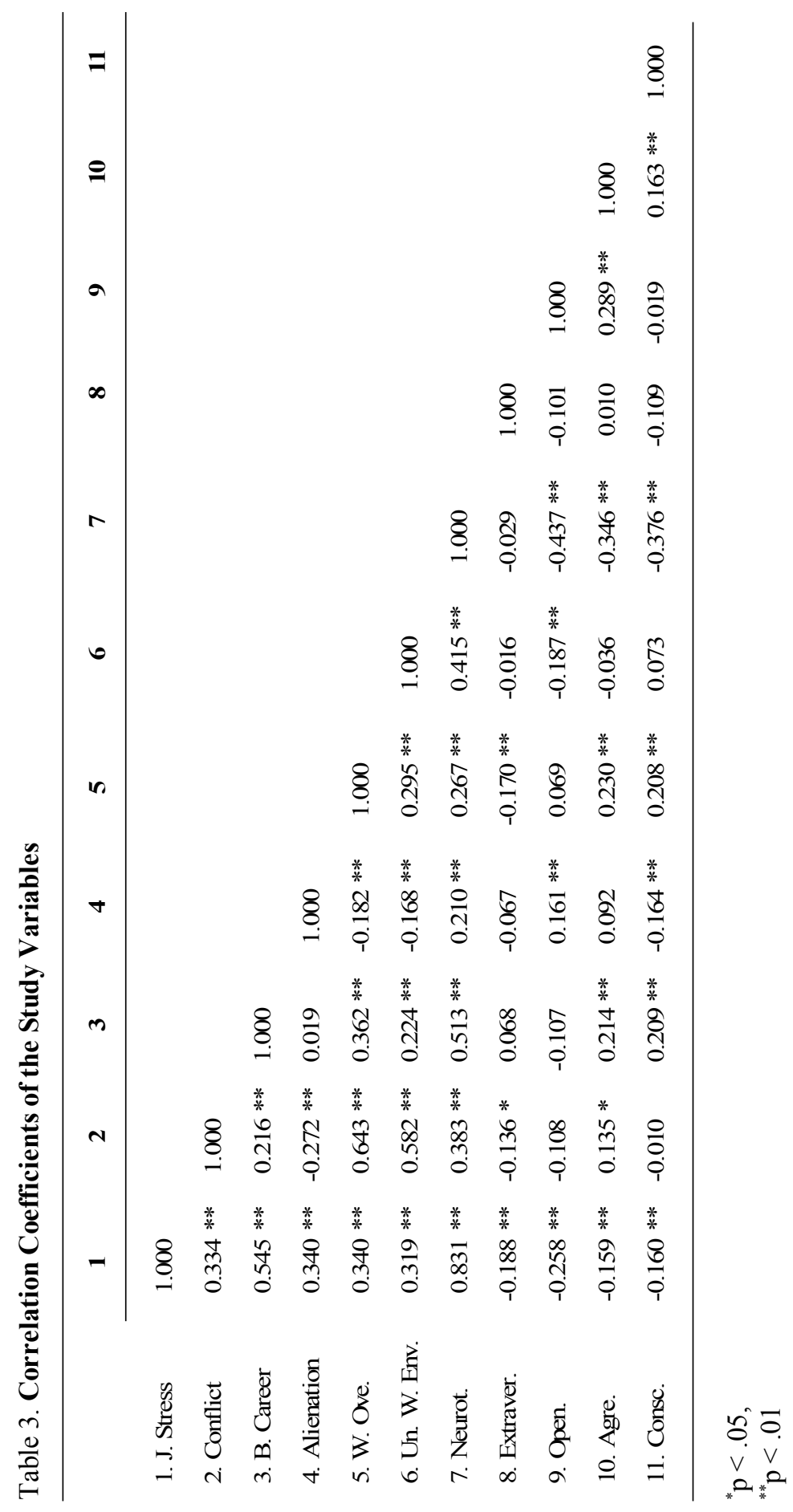


Gadjah Mada International Journal of Business, May 2004, Vol. 6, No. 2

Table 4. Results of Hierarchical Regression Analysis

\begin{tabular}{|c|c|c|c|c|}
\hline Independent Variable & $\begin{array}{l}\text { Std. Beta } \\
\text { Step } 1\end{array}$ & $\begin{array}{c}\text { Std. Beta } \\
\text { Step } 2\end{array}$ & $\begin{array}{l}\text { Std. Beta } \\
\text { Step } 3\end{array}$ & $\begin{array}{l}\text { Std. Beta } \\
\text { Step } 4\end{array}$ \\
\hline \multicolumn{5}{|l|}{ Control Variables } \\
\hline Age & $.207 *$ & $-.172 * *$ & $-.174 * *$ & $-2.592 *$ \\
\hline Marital Status $($ Single $=0$, Married $=1)$ & -.116 & $.142 *$ & $.136 *$ & $-2.299 *$ \\
\hline Number of Children & $.301 * *$ & -.225 & $-.217 * *$ & $-3.116 * *$ \\
\hline Work Experience & -.011 & $-.058 * *$ & -.072 & $-5.241 * *$ \\
\hline Job Tenure & $-.705 * *$ & $.181 * *$ & $.228 * *$ & $8.133 * *$ \\
\hline \multicolumn{5}{|l|}{ Model Variables } \\
\hline Conflict & $.126 *$ & $2.147 *$ & $9.879 * *$ & \\
\hline Blocked Career & $.395 * *$ & $6.575 * *$ & $21.984 * *$ & \\
\hline Alienation & $.298 * *$ & $7.833 * *$ & $15.023 * *$ & \\
\hline Work Overload & $.118 * *$ & $3.473 * *$ & $7.525 * *$ & \\
\hline Unfav. W. Environ. & -.011 & -.728 & $6.190 * *$ & \\
\hline Neuroticism & $.579 * *$ & $6.448 * *$ & $4.728 * *$ & \\
\hline Extraversion & $-.131 * *$ & $-3.940 * *$ & $-2.632 * *$ & \\
\hline Openness & .032 & .877 & $4.247 * *$ & \\
\hline Agreeableness & $-.131 * *$ & $-2.504 *$ & $-6.752 * *$ & \\
\hline Conscientiousness & $.133 *$ & $2.490 *$ & .224 & \\
\hline \multicolumn{5}{|l|}{ Moderating Variable } \\
\hline Gender $($ Male $=0$, Female $=1)$ & $-3.406 * *$ & $8.285 * *$ & & \\
\hline \multicolumn{5}{|l|}{ Interaction Terms } \\
\hline Gender ${ }^{*}$ Conflict & & & & $-18.267 * *$ \\
\hline Gender *Blocked Career & & & & $-21.529 * *$ \\
\hline Gender*Alienation & & & & $-12.520 * *$ \\
\hline Gender *Work Overload & & & & $-6.782 * *$ \\
\hline Gender*Unfav. W. Environ. & & & & $-9.982 * *$ \\
\hline Gender * Neuroticism & & & & $15.743 * *$ \\
\hline Gender * Extraversion & & & & $-13.091 * *$ \\
\hline Gender * Openness & & & & $-3.230 * *$ \\
\hline Gender $*$ Agreeableness & & & & $9.172 * *$ \\
\hline Gender * Conscientiousness & & & & $12.408 * *$ \\
\hline $\mathrm{R}^{2}$ & .370 & .891 & .896 & .986 \\
\hline Adj $R^{2}$ & .358 & .884 & .889 & .984 \\
\hline $\mathrm{R}^{2}$ Change & .370 & .521 & .005 & .090 \\
\hline Sig. F Change & .000 & .000 & .000 & .000 \\
\hline
\end{tabular}

$* \mathrm{p}<.05$,

$* * \mathrm{p}<.01$ 
and positive effects on stress. Openness, however, had no impact on job stress. Thus, the second hypothesis is partially supported.

In the third step, gender was entered into the equation as an independent variable in order to gauge its impact as an independent predictor. The $R^{2}$ increased from 89.1 percent to 89.6 percent indicating a change of. 5 percent, which is significant (F change $<.01)$. A closer look at the beta coefficient shows a negative value of $-3.406(p<.01)$ indicating that female managers (since the variable was initially dummy-coded as follows: female $=1$, and male $=0$ ) experience lower stress levels as compared to their male counterparts.

In the fourth and final step, the ten interaction terms were entered into the model. From Table 4, it can be seen that the additional variance explained by the ten interaction terms was 9 percent and this addition is significant $(\mathrm{F}$ change $<.01)$, indicating that there is a moderation effect. From the final regression equation, it can be observed that all interaction terms were significant at the .01 level. These results provided support for the third hypothesis of the present investigation.

\section{Moderating Effects of Gender}

Based on the information gathered from Table 4, all interaction terms were significant at the .01 level. To portray the interactions between gender and each facet of the organizational and personality variables more clearly, graphs were drawn. To draw the graphs, the facets were first recoded intothree categories namely: Low, Moderate, and High by dividing the respondents into three approximately equal groups using percentile $(0-33 \%=$ Low, $33.1-66 \%=$ Medium, and $66.1-100 \%=$ High). The results of the significant interactions are presented in Figure 2 to Figure 11.

Figure 2. Moderating Effect of Gender on the Relationship Between Conflict Level and Job Stress

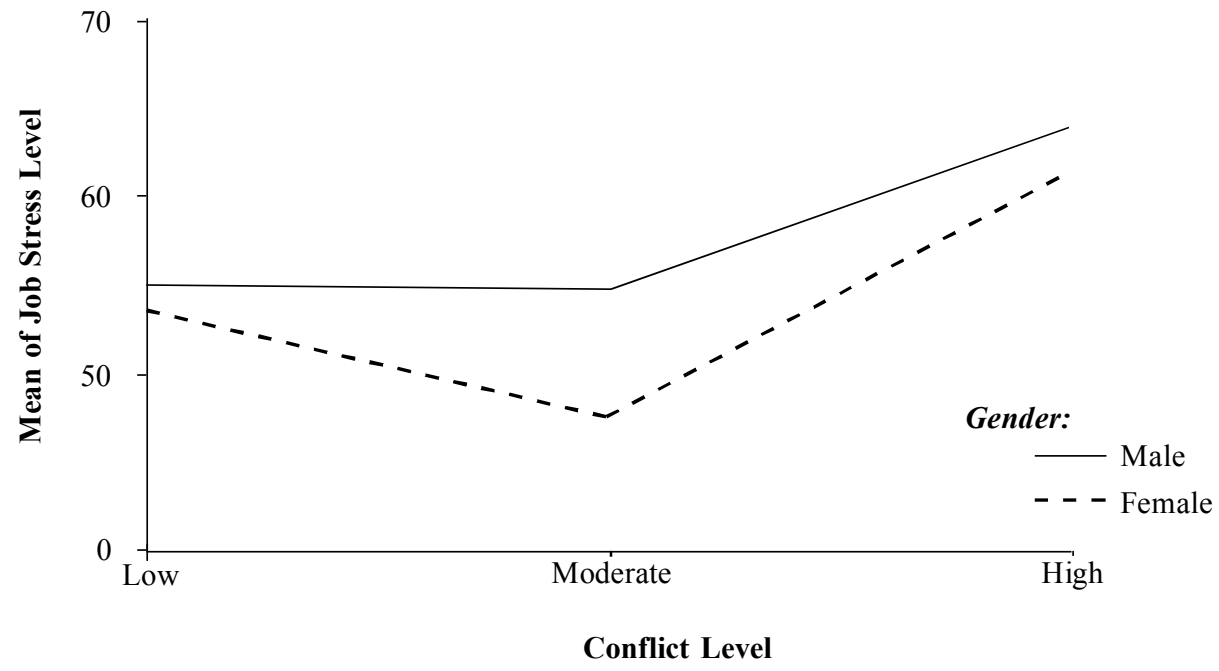


Figure 3. Moderating Effect of Gender on the Relationship Between Blocked Career Level and Job Stress

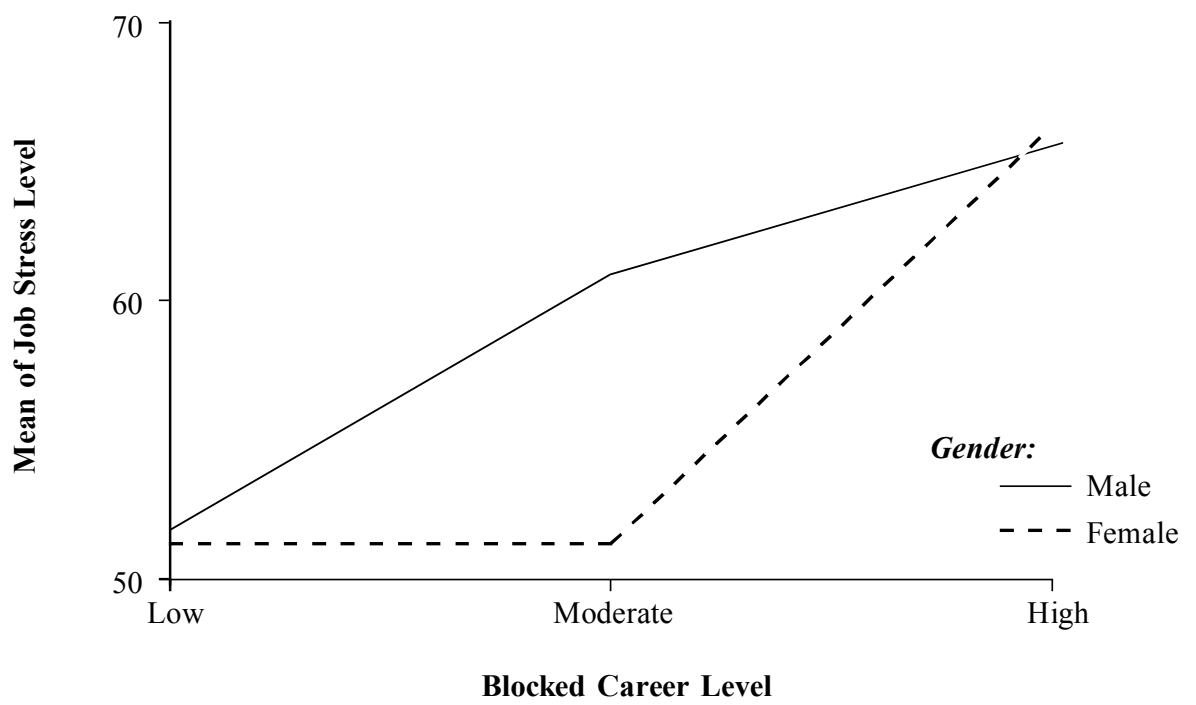

From Figure 2, it can be observed that for men, when conflict level ranges from low to moderate, their stress level remains the same. However, when the conflict level increases from moderate to high, their stress level increases at a slightly increasing rate. This implies that the stress level for men do not vary much according to conflict level. For women, the pattern is different. The stress level experienced by women decreases when the level of conflict ranges from low to moderate beyond which the stress level increases dramatically.

As shown in Figure 3, men are not tolerant to blocked career at their workplace. Specifically, their stress level increases as their perception of blocked career moves from low to high. Women, on the other hand, are more willing to tolerate career blockage. The stress level experienced by women remained constant when blocked career ranges from low to moder- ate beyond which the stress level increases sharply.

From Figure 4, it can be seen that the level of alienation does not seem to impact the stress level for men. For women, however, when alienation ranges from low to moderate, their stress level decreases. When the alienation level increases from moderate to high, the stress level experienced by women increases drastically.

As can be observed from Figure 5, men tend to be more stressful when their work overload level increases from moderate to high as compared to women who are more tolerant.

From Figure 6, it can be seen that the stress level experienced by men increases sharply when they perceived their work environment to be unfavorable beyond which this factor had no further impact on stress. The pattern of relationship between unfavorable work environment and job stress is similar for women. However, the 
Mohd. Nasurdin etal.-Organizational and Personality Effects on Managers' Job Stress

Figure 4. Moderating Effect of Gender on the Relationship Between Alienation Level and Job Stress

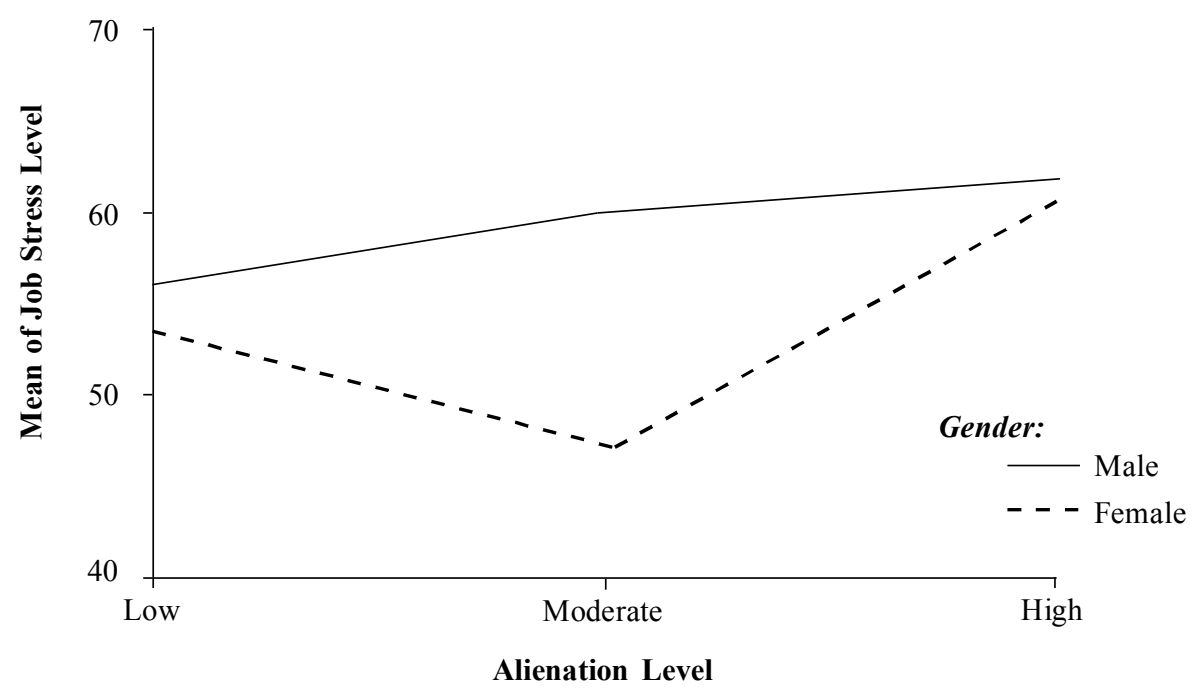

Figure 5. Moderating Effect of Gender on the Relationship Between Work Overload Level and Job Stress

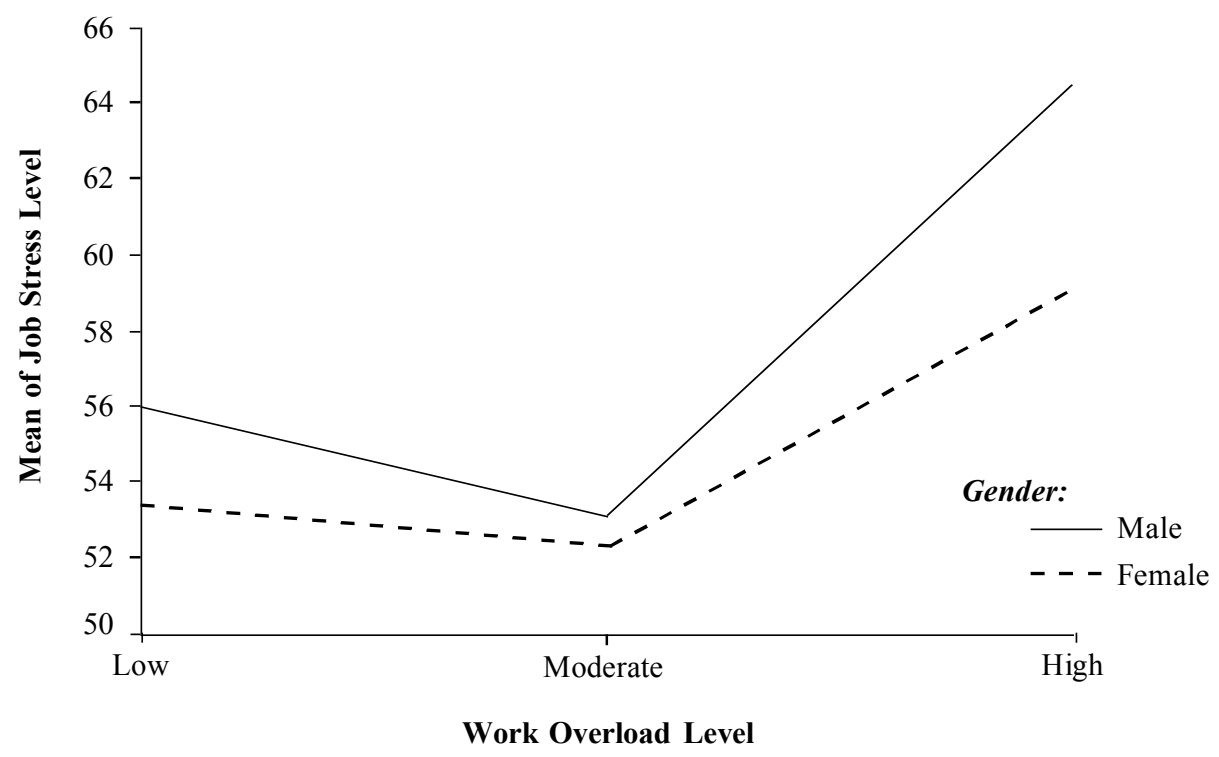


Gadjah Mada International Journal of Business, May 2004, Vol. 6, No. 2

Figure 6. Moderating Effect of Gender on the Relationship Between Unfavorable Work Environment Level and Job Stress

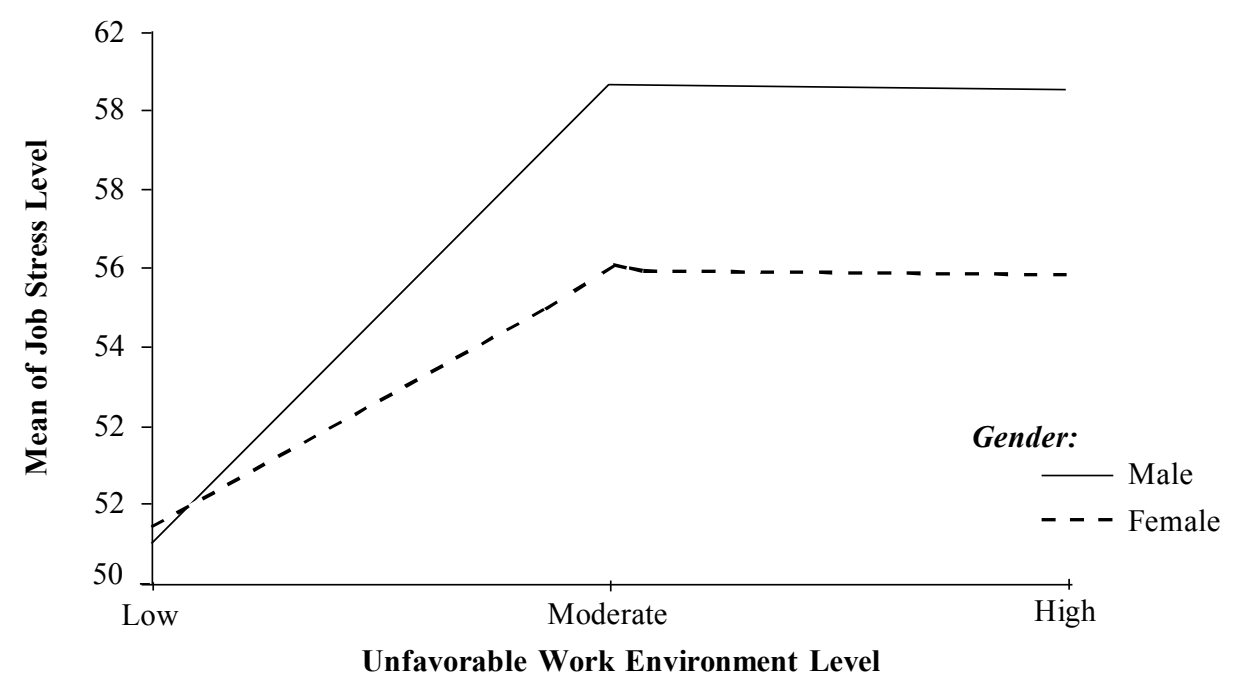

Figure 7. Moderating Effect of Gender on the Relationship Between Neuroticism Level and Job Stress

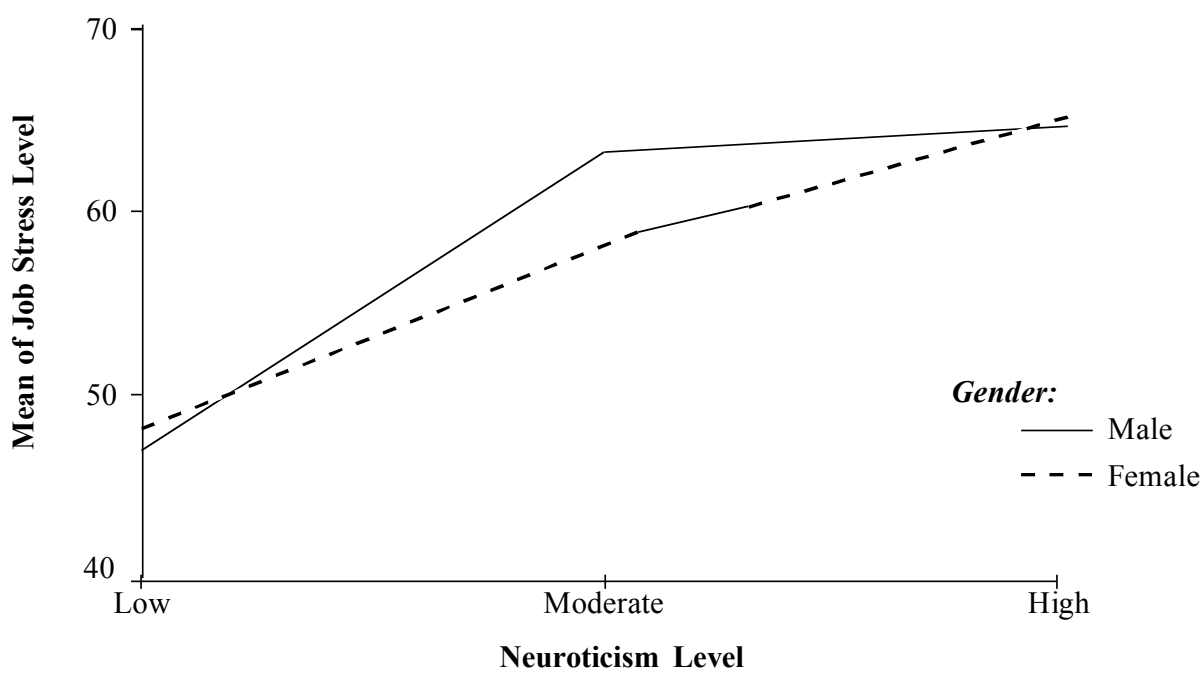

rate of change in the relationship for women is smaller compared to men.

As shown in Figure 7, women tend to become more stressful when their neuroticism level increases from low to high. For men, however, their stress level increases at an increasing rate when their neuroticism level ranges from low to moderate beyond which it has no impact on job stress. 
Mohd. Nasurdin et al.-Organizational and Personality Effects on Managers' Job Stress

As can be observed from Figure 8, men tend to exhibit higher stress when their extraversion level ranges from low to moderate whereas women tend to exhibit lower stress levels when extraversion ranges from moderate to high.
From Figure 9, the level of openness does not seem to influence stress among men. Women's stress level, on the other hand, declines as their level of openness increases from low to high. As shown in Figure 10, men tend to become more stress-

Figure 8. Moderating Effect of Gender on the Relationship Between Extraversion Level and Job Stress

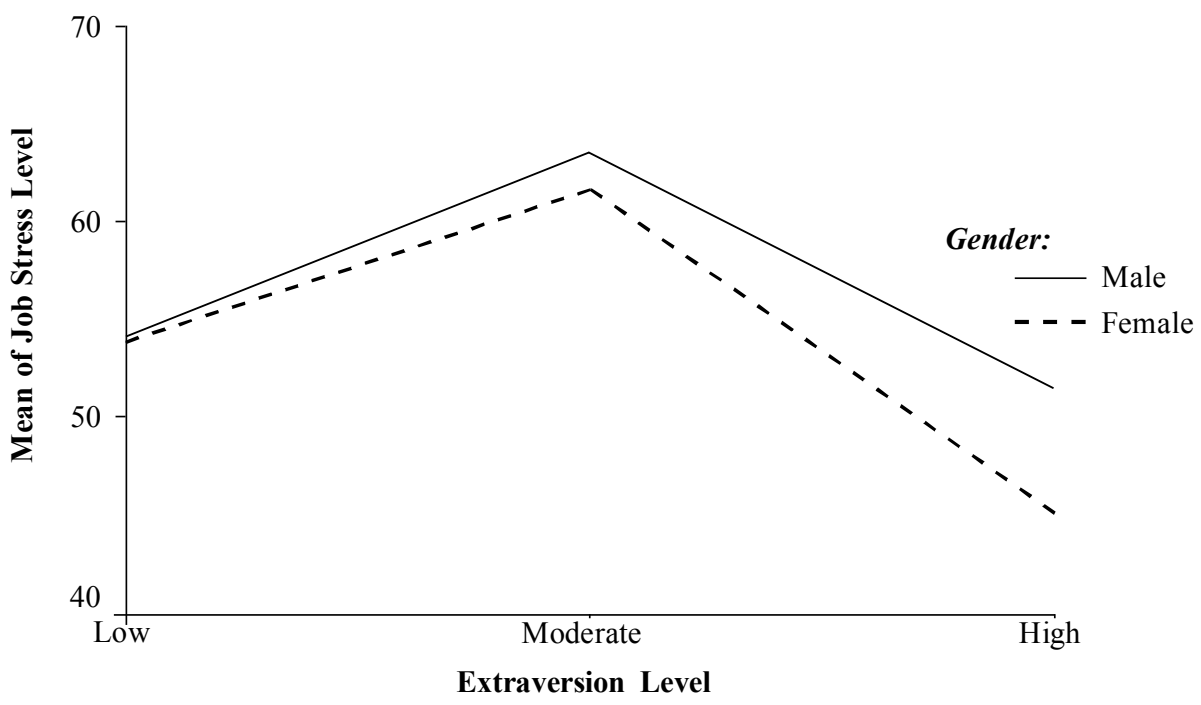

Figure 9. Moderating Effect of Gender on the Relationship Between Openness Level and Job Stress

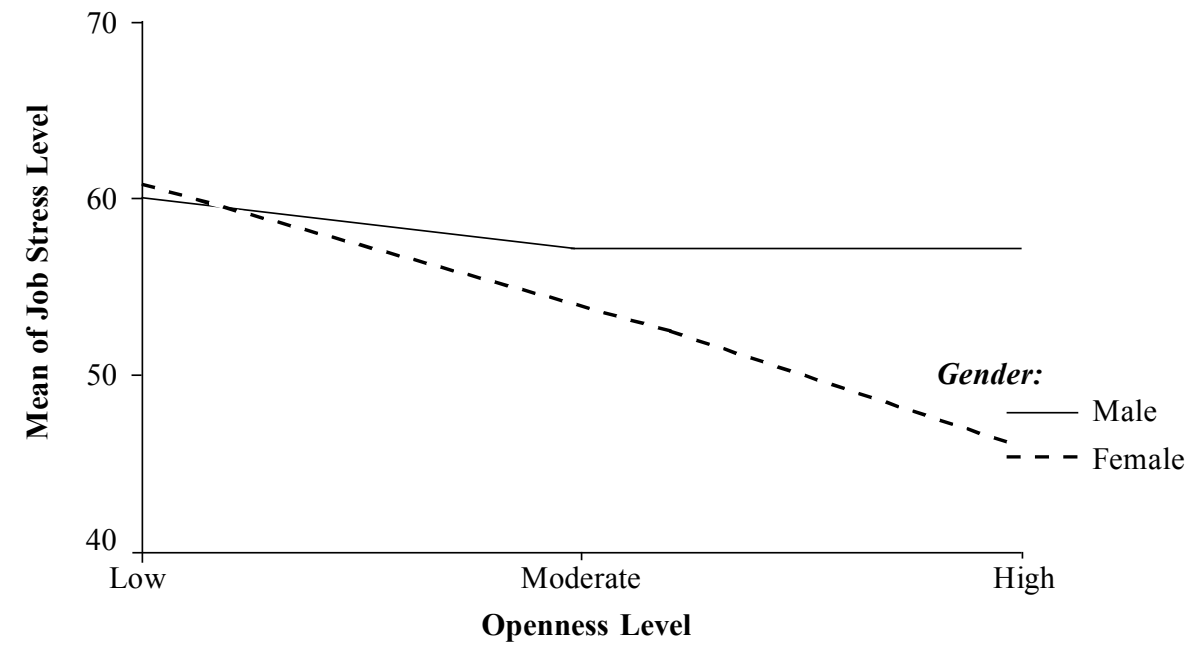


Figure 10. Moderating Effect of Gender on the Relationship Between Agreeableness Level and Job Stress

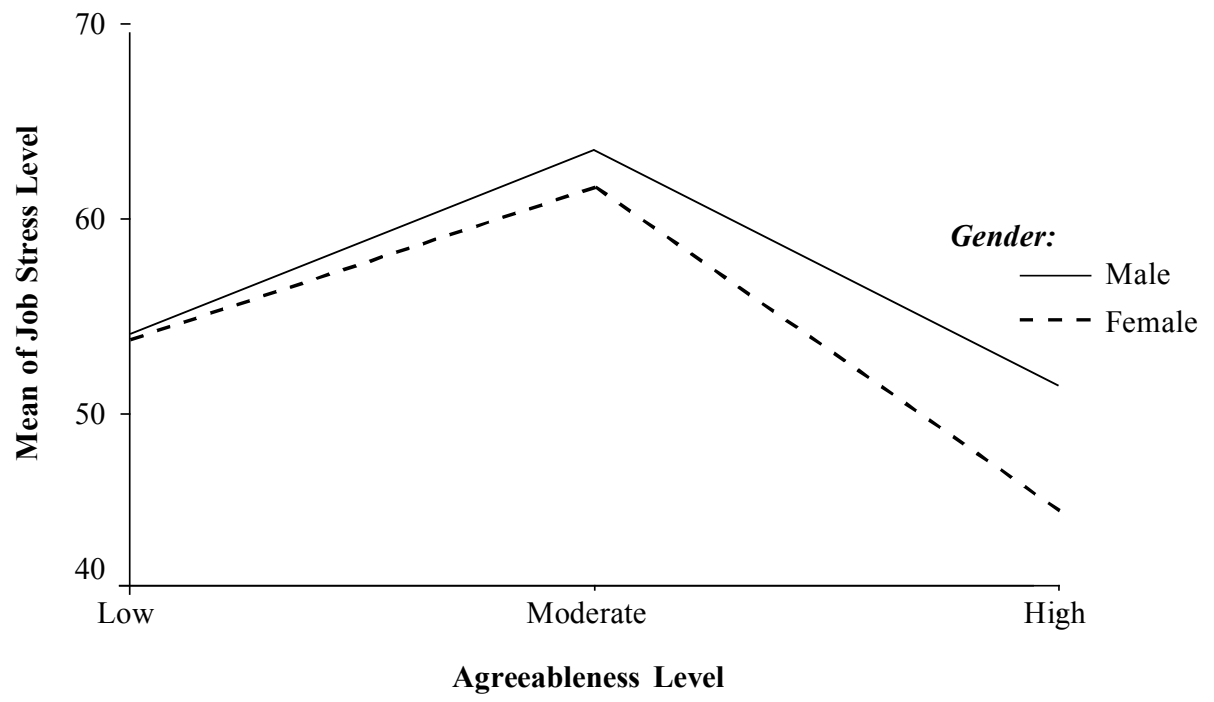

Figure 11. Moderating Effect of Gender on the Relationship Between Conscientiousness Level and Job Stress

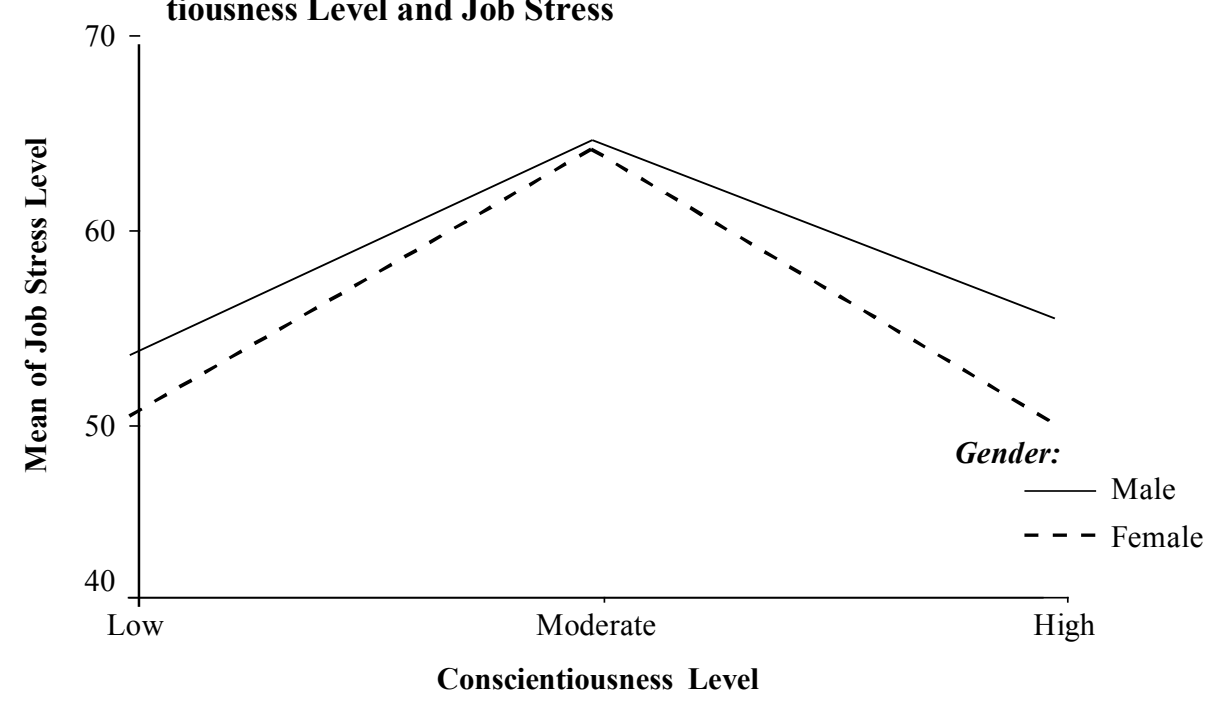

ful when their agreeableness level increases from low to moderate. On the other hand, their stress level decreases when their level of agreeableness increases from moderate to high. For women, however, their stress level decreases at a bigger rate when their agreeableness level moves from moderate to high.

From Figure 11, it can be observed that the stress level experienced by women 
tend to increase rather sharply compared to men when the conscientiousness level ranges from low to moderate but decreases at a faster rate when the conscientiousness level moves from moderate to high.

\section{Conclusion, Implications, and Limitations}

The purpose of the current study was two-fold: first, to determine the influence of organizational variables (conflict, blocked career, alienation, work overload, and unfavorable work environment) and personality variables (neuroticism, extraversion, openness, agreeableness, and conscientiousness) on job stress among managers within the electronics sector of Malaysia. Second, to test whether these relationships vary according to their gender.

The regression results from this investigation indicated that four of five organizational variables (conflict, blocked career, alienation, and work overload) had positive relationships with job stress. Hence, the first hypothesis of the study is partially supported. The finding on the positive relationship between conflict and job stress is consistent with those obtained by Roberts at al. (1997). When employees are required to fulfill conflicting role requirements, they are likely to experience job stress. This is because role conflicts create expectations that may be hard to satisfy. The finding pertaining to the positive relationship between blocked career and job stress supports those by previous researchers (Foot and Venne 1990; Rahim 1996). Seeing one's opportunities for career advancement being diminished is perceived as a threat, which in turn, leads to increased job stress. The finding on the relationship between alienation and job stress is also consistent with those discovered by prior scholars (Kanungo 1981;
Mirovsky and Ross 1986; Thoits 1995; Eugene 1999). Alienation at the workplace suggests that employees may not be able to fulfill their social needs. Thus, this sense of isolation is likely to be viewed as a threat to the individual resulting in stress. The finding pertaining to the positive relationship between poor working conditions and job stress supports those by previous researchers (Miller and Ellis 1990; Eugene 1999). The positive relationship between work overload and job stress as discovered in this study is consistent with those of prior scholars (for example, Beehr and Newman 1978; Miller and Ellis 1990; Roberts et al. 1997). A heavy workload lowers one's psychological well-being resulting in job stress. Unfavorable work environment, on the other hand, was found to have no relationship with job stress. This finding may be related to the sample itself. It is possible that managers in the electronics firms sampled may have perceived their work climate as relatively conducive. Within such a context, this variable may not be viewed as an organizational stressor.

In terms of personality variables, neuroticism had a significant and positive relationship with job stress. The finding is consistent with previous researchers (for instance, Deary and Blenkin 1996; Tellegen 1985; Birch and Kamali 2001). Individuals with elevated levels of neuroticism would be expected to be associated with higher stress since they are more likely to view stimuli as a threat to them. Conscientiousness, too, was found to have a significant and positive relationship with job stress. One plausible explanation may be due to the fact that conscientious individuals have a responsibility orientation towards work and are more likely to perceive their job responsibilities seriously, which in turn, is likely to in- 
crease their stress. In contrast, two other personality traits namely extraversion and agreeableness had significant and negative relationships with stress. The finding on the negative impact of extraversion on job stress is consistent with previous researchers (for example, Moberg 2001; Birch and Kamali 2001). Individuals who arehigh in extraversion tend to view stimuli favorably, positively, and emotionally satisfying, thereby, they are more likely to experience lower stress. The finding on the negative influence of agreeableness on job stress is consistent with previous researchers (for example, Hogan and Ones 1997; Birch and Kamali 2001). Individuals who are high in agreeableness are sympathetic, helpful, cooperative, and friendly. As such, they are more likely to feel positive towards others and more likely to experience lower stress. Openness, on the other hand, had no relationship with job stress. This finding may be related to the sample itself. Openness implies the possibility that one has to be candid and expressive in communicating ideas and feelings to others. Given that the act of preserving face has a lot of significance to Malaysians regardless of ethnicity (Abdullah 1992), they tend to be less forthcoming in expressing views and opinions. As such, openness may not be perceived as having an effect on one's stress level.

In the present study, women were discovered to experience lower stress compared to men. This finding may perhaps be attributed to the fact that there were more men $(56.8 \%)$ than women $(43.2 \%)$ managers in the electronics firms sampled. Hence, the strength of the relationships between organizational and personalityrelated stressors may have been attenuated. From Figure 2, it can be observed that for men, when conflict level ranges from low to high, their stress level do not vary sharply. For women, however, the pattern is different. The stress level experienced bywomen actually decreases when the level of conflict ranges from low to moderate beyond which the stress level increases drastically. It is plausible that working women, as opposed to men, having had to carry out their dual job-family responsibilities may become better equipped to cope with stress associated with conflict. As shown in Figure 3, for men, their stress level increases as their perception of blocked career moves from low to high. The stress level experienced by women remains constant when blocked career ranges from low to moderate beyond which the stress level increases dramatically. One possible explanation to account for this phenomenon may be related to the breadwinner role for men. Traditionally, men have been given the responsibility of being the main breadwinner for the family (Haw 1982). Thus, a blocked career will jeopardize one's ability to carry out this obligation, thereby, increasing one's stress level. From Figure 4 , it can be seen that the level of alienation does not seem to impact the stress level for men. For women, however, their stress level decreases when alienation ranges from low to moderate. As alienation level increases from moderate to high, the stress level experienced by women increases sharply. One plausiblereason for this finding is that women as discovered by Rosener (1990) may be socialized to be more sensitive to and interested in cultivating relationships with coworkers than men. Therefore, feelings of alienation in one's job maybe a frustrating experience for women, which in turn, lead to higher stress. As shown in Figure 5, men experienced higher stress when the work overload level increases from moderate to high whereas women are more tolerant. One possibility 
to account for this finding may be related to the fact that women workers have heavier burdens since they have had to fulfill both their work as well as family demands as noted by earlier scholars (for example, Terborg 1977; Haw 1982). As a result, they may have developed more enduring stress coping mechanisms.

From Figure 6, it can be seen that the stress level experienced by men increases drastically when they perceived the unfavorableness of their work environment as ranging from low to moderate beyond which unfavorable work environment had no further impact on stress. Women, too, had a similar pattern of relationship. This finding seems to suggest that unfavorable work environment is stressful for both men and women. This similarity in finding may be indicative of a trend toward homogenization of values consistent among workers of both genders, which is consistent with the findings made byprevious researchers(for instance, Rout 1999; Lee and Farh 1999). As shown in Figure 7, women tend to become more stressful when their neuroticism level increases from low to high. For men, however, their stress level increases at an increasing rate when their neuroticism level ranges from low to moderate beyond which it has no impact on job stress. This finding seems to imply that neuroticism tend to increase stress amongboth men and women even though the impact seems to be more prominent for women. This finding may be related to the fact that individuals experiencing negativeaffectivity are more likely to possess a less favorable self-view and more likely to dwell on their failures and shortcomings (Watson and Clark 1984), which in turn, lead to greater stress. From Figure 8 , it can be seen that men tend to exhibit higher stress when their extraversion level ranges from low to moderate.
Women, on the other hand, tend to exhibit lower stress level when extraversion ranges from moderate to high. This finding implies that moderate to high level of extraversion among women is preferable. One explanation for this finding is that women who are high in extraversion are more friendly and outgoing (Costa and McCrae 1992), which in turn, enables them to fulfill their greater social needs as suggested by Rosener (1990). As a result, their stress levels tend to be lower.

As can be observed from Figure 9, the level of openness does not seem to influence stress among men. However, for women, their stress level declines as their level of openness increases from low to high. This finding seems to suggest that low to high levels of openness among women is preferable. As shown in Figure 10 , for men, their stress level increases when their agreeableness level increases from low to moderate but decreases when their level of agreeableness increases from moderate to high. For women, however, their stress level decreases at a bigger rate when their agreeableness level moves from moderate to high. This finding implies that moderate to high levels of agreeableness among both men and women is preferable in reducing stress. From Figure 11, it can be observed that the stress level experienced by women tend to increase at a bigger rate as opposed to men when the conscientiousness level ranges from low to moderate but decreases at a faster rate when the conscientiousness level ranges from moderate to high. This finding suggests that moderate to high levels of conscientiousness will lead to lower stress for both men and women. This similarity in findings regarding openness and agreeableness may be indicative of a trend toward homogenization of values consistent among workers of both genders as discov- 
ered by earlier researchers (for example, Rout 1999; Lee and Farh 1999).

From the managerial point of view, the findings from this research suggest that employing organizations need to attend to organizational factors that are likely to act as job stressors. In order to reduce stress among managers, organizations should provide sufficient opportunities for their managers to move to higher positions in the organizational hierarchy, build cohesive cross-functional work teams, avoid burdening managers with heavy workloads, and communicate clearly its expectations. Given that gender did play the role of a moderator in the relationship between the organizational variables and job stress, organizations need to be careful in their placement process. For instance, employers may need to avoid placing: (1) managers of either gender in jobs that entail moderate to high levels of conflict, (2) men in jobs that have minimal prospects of career progression, (3) women in jobs that are highly alienated, (4) men in jobs that entails heavy work duties and assignments, (5) both men and women managers in an unfavorable work environment. Similarly, the findings from this investigation suggest that organizations need to attend to the individual's personality traits that are likely to induce stress.
Given that gender did play the role of a moderator in the relationship between personality dimensions and job stress, organizations need to be careful in their selection process. For example, employers may need to select candidates of either gender: (1) who experience moderate to high levels of agreeableness, and (2) who experience moderate to high levels of conscientiousness.

There are three major limitations in this research that need to be noted. First, this study makes use of cross-sectional data, which limits inferences with regards to causality between the independent variables and the dependent variable. The use of a longitudinal approach would improve the ability to make causal statements. Second, this study is limited to managers within the manufacturing industry of Malaysia. Thus, the validity of the findings cannot be generalized to other job incumbents in other sectors. Future research may be conducted to compare the predictive validity of the model across different jobs and industries. Third, given that there may be other individual, occupational, organizational, and non-work factors that also affect and moderate stress, researchers interested in this area should try to explore these factors in future.

\section{References}

Abdullah, A. 1992. Influence of ethnic values at the Malaysian workplace. In A. Abdullah (ed.) Understanding the Malaysian Workforce: Guidelines for Managers: 2-17. Kuala Lumpur: Malaysian Institute of Management.

Aun, O. E. 1998. Perceived organizational climate, teachers' locus of control and burnout. Unpublished MBA Thesis. Penang-Malaysia: Universiti Sains Malaysia.

Bank Negara Malaysia. 2001. Annual Report. 
Mohd. Nasurdin etal.-Organizational and Personality Effects on Managers' Job Stress

Bat, S. T. 1995. Effect of organizational environment and personal factors on work stress and organizational commitment. Unpublished MBA Thesis. Penang-Malaysia: Universiti Sains Malaysia.

Beehr, T. A., and J. E. Newman. 1978. Job stress, employee health and organizational effectiveness: A facet analysis, model and literature review. Personnel Psychology 31 (3): 665-699.

Birch D. N., and F. Kamali. 2001. Psychological stress, anxiety, depression, job satisfaction, and personality characteristics in pre-registration house officers. Postgraduate Medical Journal 77 (904): 109-121.

Clark, L. A., and D. Watson. 1991. Tripartite model of anxiety and depression: Psychometric evidence and taxonomic implications. Journal of Abnormal Psychology 100 (12): 316-336.

Cohen, J., and P. Cohen. 1975. Applied Multiple Regression/Correlation Analysisfor the Behavioral Sciences. New Jersey: Lawrence Erlbaum Associates.

Cook, C.W., and P. L. Hunsaker. 2001. Management and Organizational Behavior (3 ${ }^{\text {rd }}$ Ed.) New York : McGraw Hill.

Cooper, C. L., B. D. Kirkaldy, and J. Brown. 1994. A model of job stress and physical health: The role of individual differences. Personality and Individual Differences 16 (6): 653-655.

Costa, P. T., and R. R. McCrae. 1985. The NEO Personality Inventory Manual. OdessaFL: Psychological Assessment Resources, Inc.

Costa, P. T., and R. R. McCrae. 1992. Revised NEO Personality Inventory and NEO FiveFactor Inventory: Professional Manual. Odessa-FL: Psychological Assessment Resources, Inc.

Davis, M., R. E. Elizabeth, and M. Matthew. 2000. The Relaxation and Stress Reduction Workbook ( $5^{\text {th }}$ ed.). New York: New Harbinger Publications.

Deary, I. J., and H. Blenkin. 1996. Models of job-related stress and personal achievement among consultant doctors. British Journal of Psychology 87 (1): 3-29.

Eugene, J. W. 1999. The impact of work resources on job stress among correctional treatment staff. Journal of Addictions and Offender Counseling 20 (1): 26-34.

Farh, J-H., P. C. Earley, and S-C. Lin. 1997. Impetus for action: A cultural analysis of justice and organizational citizenship behavior in Chinese society. Administrative Science Quarterly 42 (3): 421-444.

Foot, D. K., and R. Venne. 1990. Population, pyramids and promotional prospects. Canadian Public Policy 14 (4): 387-398.

Goldberg, L. R. 1993. The structure of phenotypic personality traits. American Psychologist 48 (1): 26-34. 
Goldberg, D., and V. Hillier. 1978. A User's Guide to the General Health Questionnaire (GHQ). Windsor: NFER-Nelson.

Graziano, W.G., and N. H. Eisenberg. 1997. Agreeableness: A dimension of personality. In R. Hogan, J.A. Johnson, and S. Briggs (eds.). Handbook of Personality Psychology (pp. 795-824). San Diego: Academic Press.

Greenhaus, J. H., and N. J. Beutell. 1985. Sources of conflict between work and family roles. Academy of Management Review 12 (6): 120-128.

Greenhaus, J. H., A. G. Bedeian, and K. W. Mossholder. 1987. Work experiences, job performance, and feelings of personal and family well-being. Journal of Vocational Behavior 31 (7): 200-215.

Hall, K., and L. K. Savery. 1986. Tight rein, more stress. Harvard Business Review 23 (10): 1162-1164.

Haw, M. A. 1982. Women, work and stress: A review and agenda for the future. Journal of Health and Social Behavior 23: 132-144.

Hogan, J., and D. S. Ones. 1997. Conscientiousness and integrity at work. In R.Hogan, J. A. Johnson, and S. Briggs (eds.). Handbook of Personality Psychology (pp. 849870). San Diego: Academic Press.

Jestin. W., and A. Gampel. 2002. The Big Valley, Global Outlook. Toronto: McGrawHill.

Jick, T. D., and L. F. Mitz. 1985. Sex differences in work stress. Academy of Management Review 10 (1): 408-420.

John, O. P., and S. Srivastava. 1999. The big five-trait taxonomy: History, measurement, and theoretical perspective. In L. Pervis and O. John (eds.) Handbook of Personality: Theory and Research (pp. 102-138). New York: Guilford.

Kanungo, R. N. 1981. Work alienation and involvement: Problems and prospects. International Review of Applied Psychology 30: 1-15.

Kuan, O. W. 1994. The effect of marital status of working women on organizational commitment and work stress. Unpublished MBA Thesis. Penang, Malaysia: Universiti Sains Malaysia.

Lee, C., and J-L. Farh. 1999. The effects of gender in organizational justice perceptions. Journal of Organizational Behavior 20: 133-143.

Mansor, N. 1994. Women managers in malaysia: Their mobility and challenges. In N. J. Adler and D. N. Izraeli (eds.) Competitive Frontiers: Women Managers in a Global Economy (pp. 101-113). Cambridge, Massachusetts: Blackwell Publishers.

Matteson, M. T., and J. M. Ivancevich. 1999. Organizational Behavior and Management ( $5^{\text {th }}$ eds.). New York: McGraw Hill.

McCrae, R. R. 1996. Social consequences of experiential openness. Psychological Bulletin 120: 323-337. 
Mohd. Nasurdin etal.-Organizational and Personality Effects on Managers' Job Stress

Miller, K., and B. H. Ellis. 1990. An integrated model of communication, stress and burnout in the workplace. Communication Research 17 (3): 27-300.

Mirovisky, J., and E. Ross. 1986. Social patterns of distress. Annual Review of Sociology 12: 23-45.

Moberg, P. J. 2001. Linking conflict strategy to the five-factor model: Theoretical and emperical foundations. International Journal of Conflict Management 12(1): 47-68.

Murray, T. J., and D. Forbes. 1986. Where have all the middle managers gone? Dun's Business Month: 31-34.

Ngo, H-Y, and A. W-N. Tsang. 1998. Employment practices and organizational commitment: Differential Effects for men and women. The International Journal of Organizational Analysis 3: 251-266.

Northcraft, G. B., B. A. and Gutek. 1993. Point-counterpoint: Discrimination against women in management-going, going, gone or going but never gone. In E.A.Fagenson (eds.) Women in Management: Trends, Issues, and Challenges in Managerial Diversity (pp. 219-245). California: Sage.

Nunnally, J. L. 1978. Psychometric Theory (2 ${ }^{\text {nd }}$ ed.). New York: McGraw Hill.

Rahim, A. 1996. Stress, strain, and other moderators: An empirical comparison of entrepreneurs and managers. Journal of Small Business Management 34 (1): 46-58.

Roberts, J. A., R. A. Lapidus, and L. B. Chonko. 1997. Salesperson and stress: The moderating role of locus of control on work stressors and felt stress. Journal of Marketing Theory and Practice 5 (3): 93-108.

Robbins, S. P. 2001. Organizational Behavior ( $9^{\text {th }}$ ed.). New Jersey: Prentice-Hall, Inc.

Rout, U. 1999. Gender differences in stress, satisfaction and mental wellbeing among general practitioners in England. Psychology, Health and Medicine 4 (4): 345-354.

Rosener, J. B. 1990. Ways women lead. Harvard Business Review: 119-125.

Sashkin, M. 1984. Participative management is an ethical imperative. Organizational Dynamics 12 (2): 5-22.

Selye, H. 1976. The Stress of Life. New York: McGraw Hill.

Smith, P. L., S. J. Stanley, and H. Frank. 1998. Employee work attitudes: The subtle influence of gender. Human Relations 51 (5): 649-667.

Tellegen, A. 1985. Structures of mood and personality and their relevance to assessing anxiety with an emphasis on self-report. In A. H. Tuma and J. D. Maser (eds.) Anxiety and Anxiety Disorders (pp. 681-706). Hillsdale, New York: Erlbaum.

Terborg, J. T. 1977. Women in management: A research review. Journal of Applied Psychology 62: 647-664.

Thoits, P. 1995. Stress, coping, and social support processes: Where are we? What next?. Journal of Health and Social Behavior 36 (1): 53-79. 
Gadjah Mada International Journal of Business, May 2004, Vol. 6, No. 2

Watson, D., and L. A. Clark. 1984. Negative affectivity: The disposition to experience aversive emotional states. Psychological Bulletin 96: 465-490.

Watson, D., and L. A. Clark. 1997. Extraversion and its positive emotional core. In R. Hogan, J. A. Johnson, and S. Briggs (eds.) Handbook of Personality Psychology: 767-794). San Diego: Academic Press.

Yahya, R. 1998. Organizational factors that contribute to teachers' stress. Unpublished MBA Thesis. Penang, Malaysia: Universiti Sains Malaysia. 